\title{
The Research on Cognition Design in Chinese Opera Mask
}

\author{
Tai-Jui Wang ${ }^{1}$, Yu-Ju Lin², and Jun-Liang Chen ${ }^{2}$ \\ ${ }^{1}$ Department of Mass Communication, Chinese Culture University \\ Yang-Ming-Shan, Taipei 11114, Taiwan \\ ${ }^{2}$ Graduate School of Creative Industry Design, National Taiwan University of Art \\ Ban-Ciao City, Taipei 22058, Taiwan \\ tyraywang@gmail.com
}

\begin{abstract}
Making up a facial symbolism is a very specific skill and makeup art in the Chinese opera. The performers use colorful paintings to paint variety of symbolism and line arts on their faces. These emphasize the characteristics, positions, ages, and the provenances of the characters. The method of this research applies the content analysis method to comprise a literature review of the painted-face of Jing role in the Chinese opera. The literature review has been handled and coded using the qualitative data analysis software NVivo 10. The results of this research found some indication by painted-face attribute values comparison, sources diversity reference, and nodes clustered by attribute value for indicating similarity or unusual from the original texts. In conclude the object of analysis in this research, the facial patterns which appear on the face of a Jing character, can be defined as "descriptive", "hereditary", "imitative", and "name-based" in generally. To the uninitiated audience, the face patterns and colors, which appear upon the stage, may rapidly become an indistinguishable blur. Fortunately in performer's position, one has to unravel the secrets of Chinese face painting is to learn to recognize the symbols and signs stamped upon each Chinese opera character's face.
\end{abstract}

Keywords: Chinese opera, Painted-face, Facial Symbolism, Content Analysis.

\section{$1 \quad$ Introduction}

For the ritual purposes in worldwide, masks and facial makeup are common in singing and dancing activities in different cultures. Throughout the human history, the masquerades in Europe and the facial makeup of American Indians both enjoy a long makeup experiences. But in Chinese society, mask and facial makeup were assimilated into traditional opera and developed along a unique and magnificence path. Scholars of Chinese opera are unable for certain to say where the tradition of painted-face of Chinese opera came about, but they seem surmise it began with the wearing of masks for the battle of war in Chinese ancient times. The earliest record of mask wearing dates to the Zhou Dynasty (1046-256 BC), during which masks were worn when stories about ghosts and gods were performed. Another historical story mentions King Lanling of the Northern Qi Dynasty (550-577). It seems King Lanling 
was a brave warrior, but his facial appearance was quite feminine, and he found it difficult to be intimidating in a battle. He eventually took to wearing a horrify mask when riding on his horse showed in every combat after all. The legend of King Lanling somehow gave rise to a form of song and dance performance well known as "Big Face". During the Tang Dynasty (618-907), "Big Face" performances were popular, as they were believed to confer good fortune upon Tang soldiers to embark upon a military campaign. "Big Face" performers who used their teeth to keep the masks in place wore wooden masks [1]. Hampered by the necessity of using their mouths, mask-wearers could not sing. Later, Masks and makeup were universal for the zaju (a variety play consisting of a prelude, the main play in one or two scenes, and a musical epilogue) by the time of the Song (960-1279) and Jin (1115-1234) dynasties [2]. After the formation of northern zaju and southern drama, the techniques of masks and makeup were improved incessantly. The masks were abandoned in favor of face painting. It applied directly to the face as actors began to both sing and dance during the performances. From the very beginning of the face painting, there are only four colors of pace painting were used which are red, white, black and blue. Over time, the patterns and colors employed were stylized and standardized from generation to generation [3], and the transformations of Chinese opera painted-faces design were different during the Periods (see Fig. 1).

According to the above historical records, such progress from those masks made by wood, or to the practice of face paintings on a real human face, the painted-face of Chinese opera does transformed by some factors not only from the artist themselves but also the social aspect both in life styles of audience and artificial techniques. Thus, the purpose of this research is not going to discuss about the sociology of historical aspects but focus on analyzing the fundamental basis of cognition design about the painted-face of Chinese opera performances.

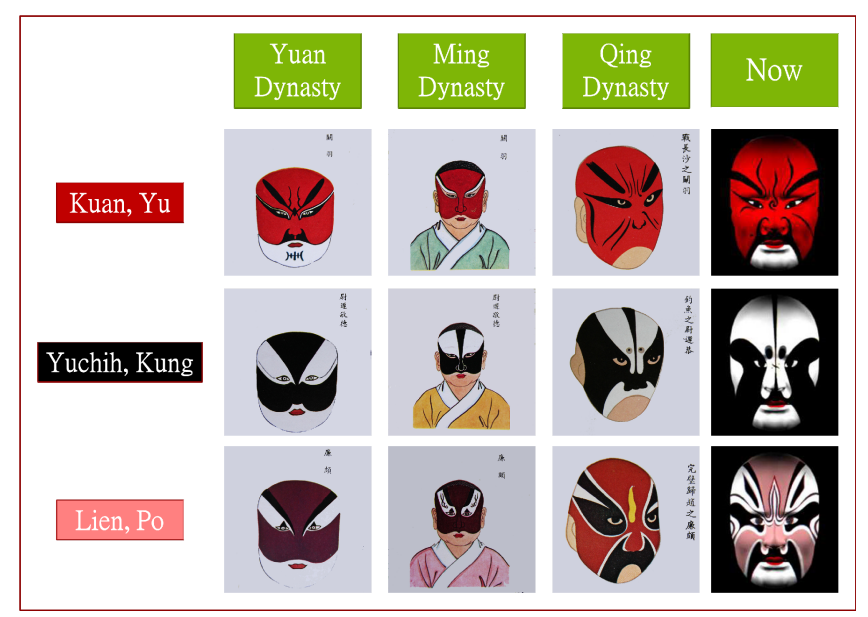

Fig. 1. The Transformation of Chinese Opera Painted-faces Design during different Periods 


\section{$2 \quad$ Literature Review}

\subsection{The Extraordinary Appearance of Chinese Opera Mask}

To talk about traditional aesthetics of facial symbolism in Chinese opera, the colors of the facial symbolism especially stand for the personalities and the characteristics [1]. For examples, the red means the loyalty and righteousness, like Kuan, Yu had a red face (the martial god in Chinese society) in the time of Three Kingdoms period (220-280). The green face means the violent man. The blue face means fierce and insidious characteristics. The black face means straight-minded. The yellow face means slyness. The golden and silver color on the face means the characters are are the roles of Chinese fairy. The purple face means steadiness. The white face means very bogus and evil man like Tsao Tsao for example.

Making up a facial symbolism is a very specific skill and makeup art in the Chinese opera. The performers use colorful paintings to paint variety of symbolism and line arts on their faces. These emphasize the characteristics, positions, ages, and the provenances of the characters. This kind of characters is called "Jing" or "Hualian" (painted-face role) by Chinese opera professional. Each kind of painted-faces has its own specific way of makeup called "Facial Symbolism". Every facial symbolism of the paintings and the drawings of Jing characters have different styles. They will be painted on the parts of performers' face (forehead, the two sides of the nose, cheeks, eyebrows, and mouth). Generally speaking, there are four kinds of characteristics of the characters by the facial symbolism in the Chinese opera: the furious and raging people, the bad guys, ghosts and fairy figures and those who showed up in the histories and fictions. In general, the less colorful and complicated the painted-faces are, the higher positions the characters are, and the steadier personalities the characters are. On the contrary, the more colorful and complicated the painted-faces are, the lower positions the characters are, and the more violent characteristics the characters are.

In this research, we were not include all of the painted-faces from the texts that we found but choose only 48 painted-faces of characters [4], whom had with background story, out of a total 500 more (see Fig. 2).

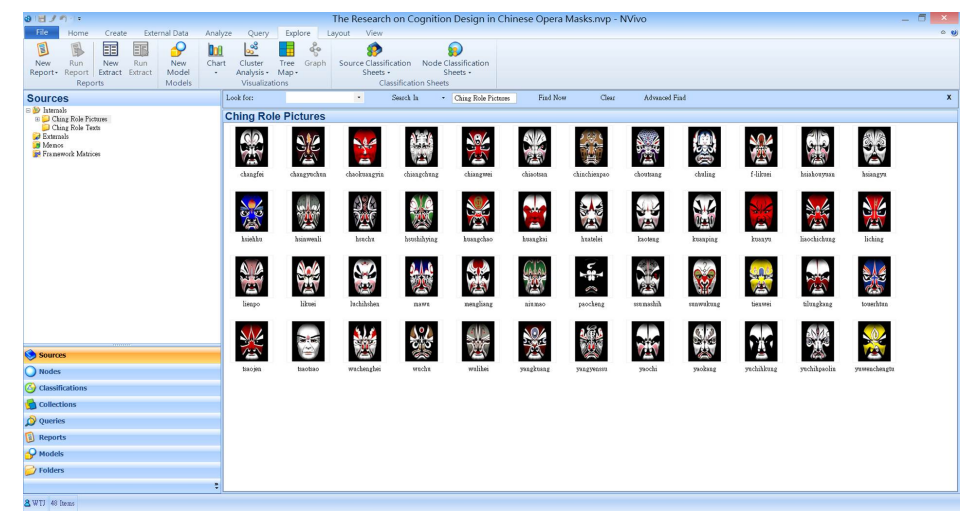

Fig. 2. The Visual Sources of 48 Painted-faces in Nvivo10 Software 


\subsection{The Combinations of Facial Symbolism in Chinese Opera}

Art historians have commented that Chinese artists traditionally seemed less interested in creating realistic depictions of the natural world, and more concerned with capturing the spirit or essence of an object [1]. As shown in table 1 and 2, we indicate categories of texts that the major colors, facial patterns, eyebrows, eyes, foreheads, nose, and mouth were represent different parts of facial painting in Chinese opera.

Table 1. The Attributes of Classification Comparison

\begin{tabular}{ll}
\hline Colors & Black, Blue, Gold, Gray, Green, Light-green, Ocher, Oil-white, Pink, Purple, Red, Silver, White, Yellow \\
\hline Facial & Fractured, Genie, Monk, Numeral Six, Numeral Ten, Ruined, Solid, Three-tile, Unique, Variegated, \\
Patterns & Villainous \\
\hline Eyebrows & Basic Eyebrows, Bat Eyebrows, Buddhist Swastika Eyebrows, Butterfly Eyebrows, Cudgel Eyebrows, Dot \\
& $\begin{array}{l}\text { Eyebrows, Downward-sloping Eyebrows, Duck's Egg Eyebrows, Elderly Eyebrows, Fire Eyebrows, } \\
\text { Gourd Eyebrows, Ladle Eyebrows, Numeral One Eyebrows, Praying Mantis Pincher Eyebrows, Ran- } \\
\text { dom Eyebrows, Reclining Silkworm Eyebrows, Saw-toothed Eyebrows, Sky-piercing Eyebrows, }\end{array}$ \\
& $\begin{array}{l}\text { Sword Eyebrows, Tiger-hook Eyebrows, Triangular Eyebrows, Uneven Eyebrows, Villain Eyebrows, } \\
\text { Willow-leaf Eyebrows, Wolf's Tooth Eyebrows }\end{array}$ \\
\hline Byes & Straight Eyes, Villain Eyes \\
\hline Foreheads & $\begin{array}{l}\text { Bat Forehead, Blue-green Forehead, Eight Trigrams Forehead, Fire Forehead, Gold Coin Forehead, } \\
\text { Golden Forehead, Good Fortune Forehead, Gourd Forehead, Long-life Forehead, Marred Forehead, } \\
\text { Moon Forehead, Original Form Forehead, Peach Forehead, Random Forehead, Red Forehead, T'ai Chi } \\
\text { Forehead, Tiger Forehead, True Nature Forehead }\end{array}$ \\
\hline Nose & $\begin{array}{l}\text { Basic Nose, Curled Nose, Full Nose, Hooked Nose, Laughing Nose, Long or Short Nose, Villain Nose } \\
\text { Mouth }\end{array}$ \\
$\begin{array}{l}\text { Bird Mouth, Crooked Mouth, Disdainful Mouth, Fire Brazier Mouth, Gold Ingot Mouth, Tiger Mouth, } \\
\text { Water Chestnut Mouth, Bearded }\end{array}$ \\
\hline
\end{tabular}

\subsection{The Processes of Painted-Face in Chinese Opera}

A typical make-up kit contains brushes, water-based paints, powder and oil-based paints [1]. The facial patterns of a Jing character are most often painted on with a brush, but they can be applied by hand as well. Although the basic pattern for a particular character is standardized, the face-painter must take into account the individual shape and features of the face upon which he is working. Figure 3 shows the basic steps for the make-up of four main roles in Chinese opera performance. For the Jing role, Kao Teng, the make-up processes are: 1.) A base of white powder is applied, and black powder is applied around the eyes to prevent oil-based make-up from seeping into them during a performance; additional black powder is applied under the nose to prevent the beard slipping off from the actor's face. 2.) A brush dipped in white paint is used to draw the approximate position of the eyebrows, eyes, nose, and facial patterns. 3.) Black oil-based paint is applied to the unpainted areas. 4.) Another layer of white paint is added to set the facial pattern in place. 5.) Pink powder is dusted onto the cheeks over the white paint. 6.) A single line of oil-based red paint is applied to the forehead [4]. 
Table 2. The Facial Pattern Distribution of 48 Jing Roles

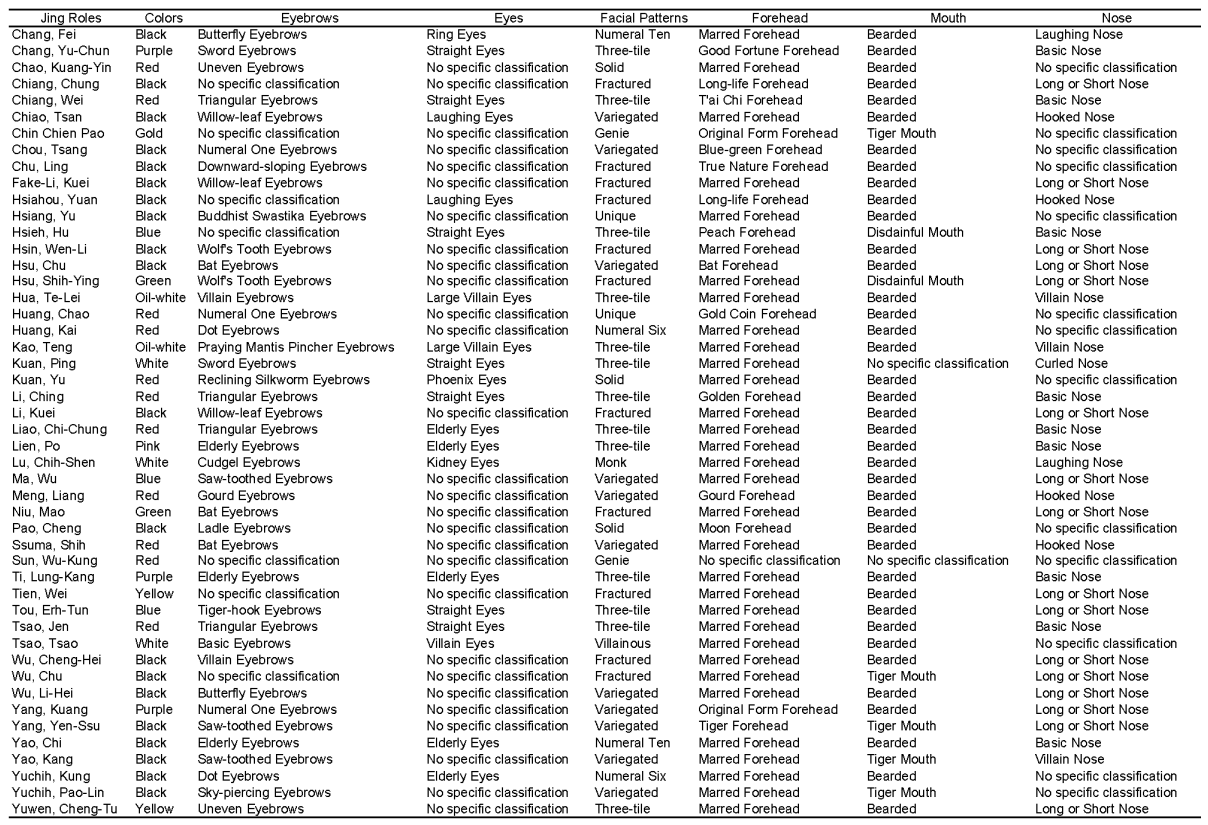

Above categorized and listed painted-face sources were by Nvivo10 software

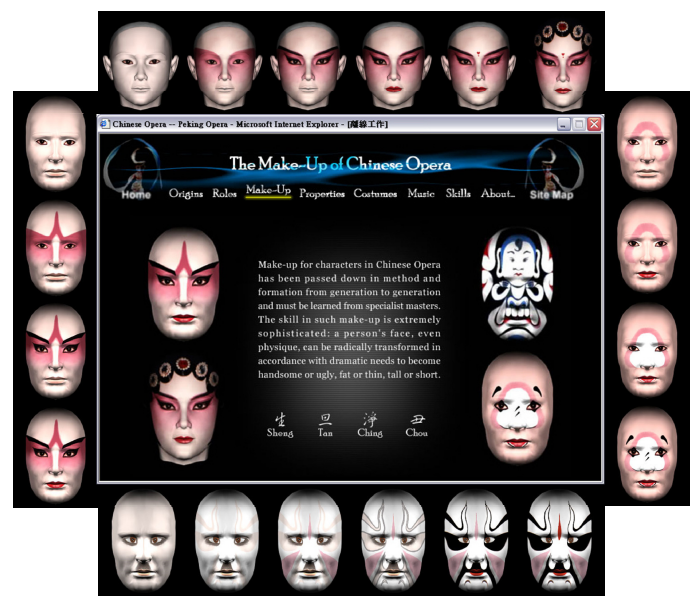

Fig. 3. The Make-up Steps of the Four Main Roles in Chinese Opera 


\section{$3 \quad$ Research Methods}

Content analysis is one of the most direct methods of textual analysis which can be applied to a range of media and cultural artifacts. But the main weakness of content analysis to date has been that it is very laborious: coding hundreds of facial graphics and texts of Chinese opera can be very time-consuming [5]. So, this research comprises a literature review of the painted-face of Jing role in the Chinese opera. The literature review has been handled and coded using the qualitative data analysis software NVivo 10. It was easier with counting and classifying for the texts. In the first phase will be import 48 visual sources then processed the codes and nodes by selected texts of that in the software. Second will be query and analysis of literature exploring the necessity of researching on the Jing role in Chinese opera culture, the obligation of the research orientation to develop guidelines for this research, and the unique aspects of the painted-face that complicate the process of cognition design those mask painting methodology. The third phase will be find out some indication by attribute values comparison, sources diversity reference, and nodes clustered by attribute value for indicating similarity or unusual from the original texts.

\section{$4 \quad$ Findings and Discussion}

The facial patterns of Jing role are highly stylized and resemble not at all an actual person's face. This is the beauty of face painting in Chinese opera. By sacrificing realism, the artists of Chinese opera are able to capture the inner nature of a character in all its glory or ugliness. The object of analysis in this research, the facial patterns which appear on the face of a Jing character, can be defined as "descriptive", "hereditary", "imitative", and "name-based" in generally.

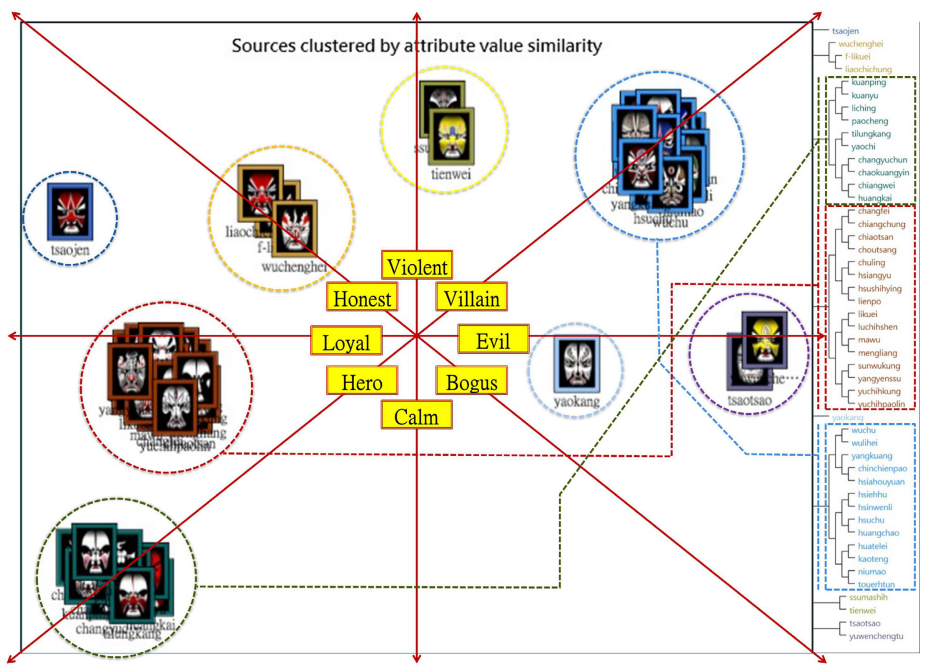

Fig. 4. The Clustered Comparison of Personality Types 


\subsection{Descriptive}

The faces of most opera characters are designed to be illustrative of their personality. For example, villains have white faces to symbolize their cold-bloodedness. The character Hsiang, $\mathrm{Yu}$, who were in the time of Chu Kingdom during the period of Warring States (1030-223 BC), is depicted with an iron trident inscribed upon his forehead to symbolize his great strength and proclivity towards violent action. The coding of personalities in this research are categorized as "hero", "villain", "violent", "calm", "loyal", "evil", "honest", and "bogus". The findings in this approach as shown in Figure 4, the clustered comparison of personality types are based on the attribute value similarities of painted-face in Chinese opera. It indicates that the character Tsio, Jen is a villain man but had a loyal personality. On the contrary, the character Yao, Kang is a hero but had bad inner personalities. The rest painted-faces of the results are indicated with each other to each group as by personality attributes.

\subsection{Hereditary}

Father and son characters feature similar facial patterns and colors to indicate a family resemblance. In such a case, a character's face may not be a true indicator of his personality. As shown in figure 5, both groups are in the relationship of father and son. But frankly, fewer items as shown in the facial pattern comparison of father and son are really not a true indicator of personality.

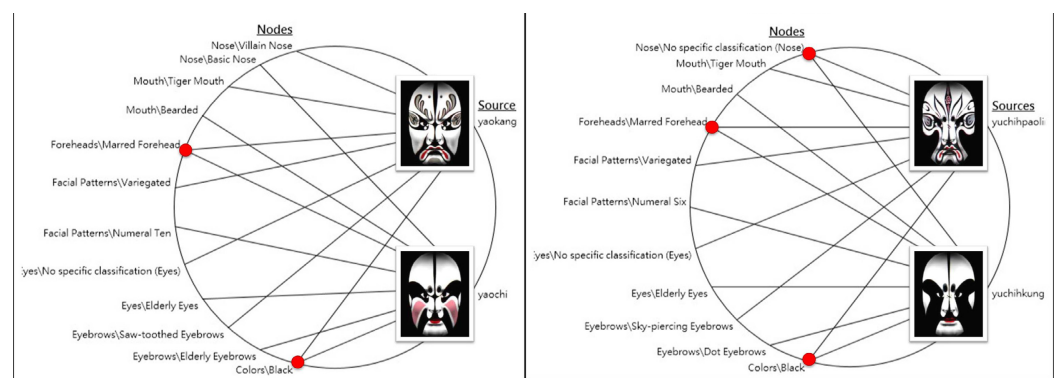

Fig. 5. The Facial Pattern Comparison of Father and Son

\subsection{Imitative}

When two characters are similar in personalities and behaviors, they may be made up to resemble one another. This is the case with the characters $\mathrm{Li}, \mathrm{Kuei}$ and his imposter, $\mathrm{Li}$, Kuei, as well as for the characters Chang, Fei and Chiao, Tsan. According to the texts, the latter two are so similar in personality that their painted-faces are identical with each other but the exception of that Chang, Fei has large eyes while Chiao, Tsan has small eyes [1]. As shown in table 3, we found out the first two characters mentioned above are all at same categories, but the second two characters are the same in the fewer items.

So, we used a model for indicating clearly the patterns of Chang, Fei and Chiao, Tsan as shown in figure 6. It shows these two characters' personalities are the same types. But in the facial pattern parts are not really at the same categories. So, we tried to dig in more by scientific way on the quantitative method, Pearson Correlation 
Coefficient, in the Nvivo 10 software. The findings are shown in table 4 and figure 7 to evident more about this unusual issue that these two characters are not exactly the same in nowadays even they were same in the past.

Table 3. The Attributes of Classification Comparison

\begin{tabular}{|c|c|c|c|c|c|c|c|}
\hline $\begin{array}{l}\text { Painted-face } \\
\text { (All Attributes) }\end{array}$ & Colors & $\begin{array}{c}\text { Facial } \\
\text { Patterns }\end{array}$ & Eyebrows & Eyes & Forehead & Nose & Mouth \\
\hline Chang, Fei & Black & $\begin{array}{c}\text { Numeral } \\
\text { Ten }\end{array}$ & $\begin{array}{l}\text { Butterfly } \\
\text { Eyebrows }\end{array}$ & $\begin{array}{l}\text { Ring } \\
\text { Eyes }\end{array}$ & $\begin{array}{c}\text { Marred } \\
\text { Forehead }\end{array}$ & $\begin{array}{l}\text { Laughing } \\
\text { Nose }\end{array}$ & Bearded \\
\hline Chiao, Tsan & Black & Variegated & $\begin{array}{l}\text { Willow-leaf } \\
\text { Eyebrows }\end{array}$ & $\begin{array}{c}\text { Laughing } \\
\text { Eyes }\end{array}$ & $\begin{array}{c}\text { Marred } \\
\text { Forehead }\end{array}$ & $\begin{array}{l}\text { Hooked } \\
\text { Nose }\end{array}$ & Bearded \\
\hline Li, Kuei & Black & Fractured & $\begin{array}{l}\text { Willow-leaf } \\
\text { Eyebrows }\end{array}$ & $\begin{array}{c}\text { No } \\
\text { specific }\end{array}$ & Fractured & $\begin{array}{c}\text { Long or } \\
\text { Short }\end{array}$ & Bearded \\
\hline $\begin{array}{l}\mathrm{Li}, \text { Kuei } \\
\text { (imposter) }\end{array}$ & Black & Fractured & $\begin{array}{l}\text { Willow-leaf } \\
\text { Eyebrows }\end{array}$ & $\begin{array}{c}\text { No } \\
\text { specific }\end{array}$ & Fractured & $\begin{array}{c}\text { Long or } \\
\text { Short }\end{array}$ & Bearded \\
\hline
\end{tabular}

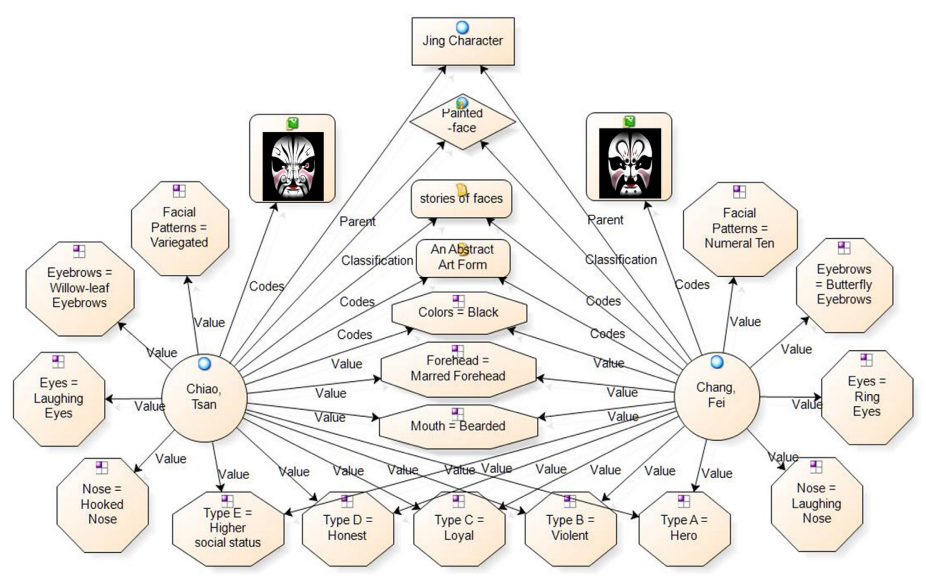

Fig. 6. The Face Design Comparison of Chang, Fei \& Chiao, Tsan

Table 4. The Clustered Comparison of Chang, Fei and Chiao, Tsan

\begin{tabular}{cc}
\hline Clustered Comparison & Pearson Correlation Coefficient \\
\hline By Word Similarity & 0.5 \\
By coding Similarity & -0.769231 \\
By Attribute Value Similarity & 0.381513 \\
By Attribute Value Similarity (with Types A to E) & 0.626667 \\
\hline
\end{tabular}




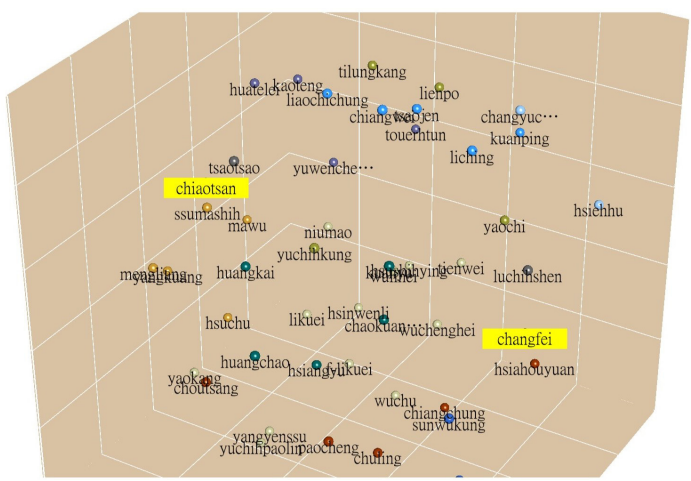

Fig. 7. The Clustered Comparison by Coding Similarity of Chang, Fei \& Chiao, Tsan

\subsection{Name-Based}

According to the texts, often a character's name or nickname influences the look of the character's face in Chinese opera performance [1]. In a case that keeping with his nickname "Green-faced Tiger", the character Hsu Shih-ying is depicted with a green face as shown in figure 8, while coding stripes were analyzed in the Nvivo 10 software.

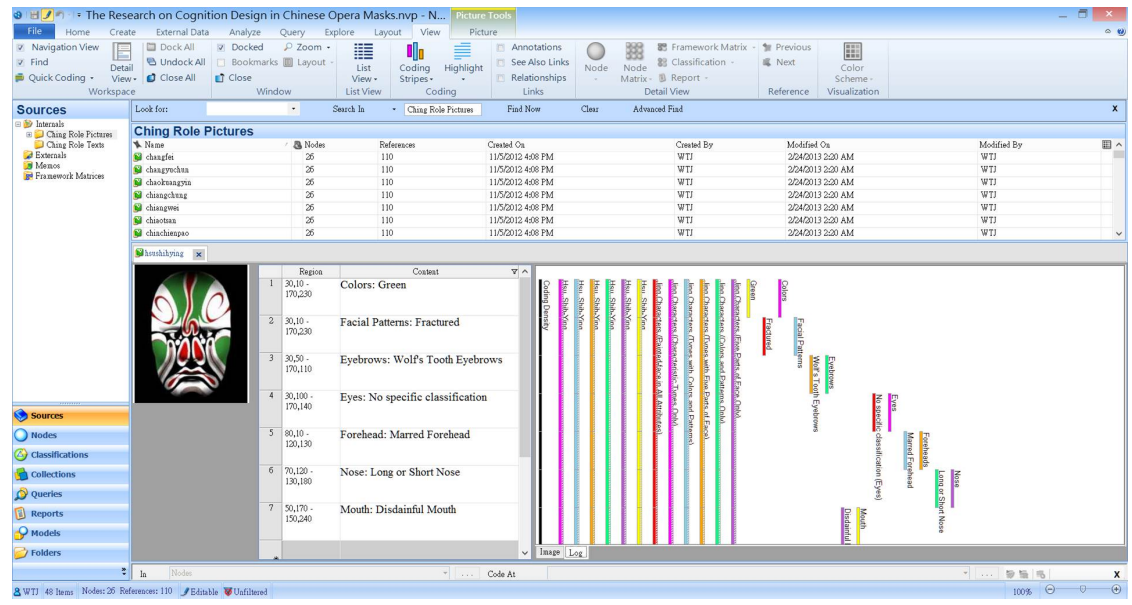

Fig. 8. Jing Role's coding stripes: "Green-faced Tiger" (Hsu, Shih-ying)

\section{Conclusion}

After the limitation of this content analysis research, firstly we could conclude to the uninitiated audience, the face patterns and colors, which appear upon the stage, may rapidly become an indistinguishable blur. Fortunately in performer's position, one has to unravel the secrets of Chinese face painting is to learn to recognize the symbols and 
signs stamped upon each Chinese opera character's face. Such makeup for characters in Chinese opera has been passed down in methods and formations from generation to generation and must be learned from specialist masters.

So, the skill in such makeup is extremely sophisticated: a person's face, even physique, can be radically transformed in accordance with dramatic needs to become handsome or ugly, fat or thin, tall or short. What makes Jing characters such a colorful and fascinating part of Chinese opera is the fact that the patterns painted upon their faces are very revealing of their personalities in different attribute value combinations (See Figure 9). Whether the characters are hero or villain, calm or violent, loyal or evil, honest or bogus, higher or lower social status, an experienced viewer of Chinese opera has only to glance upon the face of a Jing character to know his true nature only by two attributes, colors and facial patterns, are good enough.

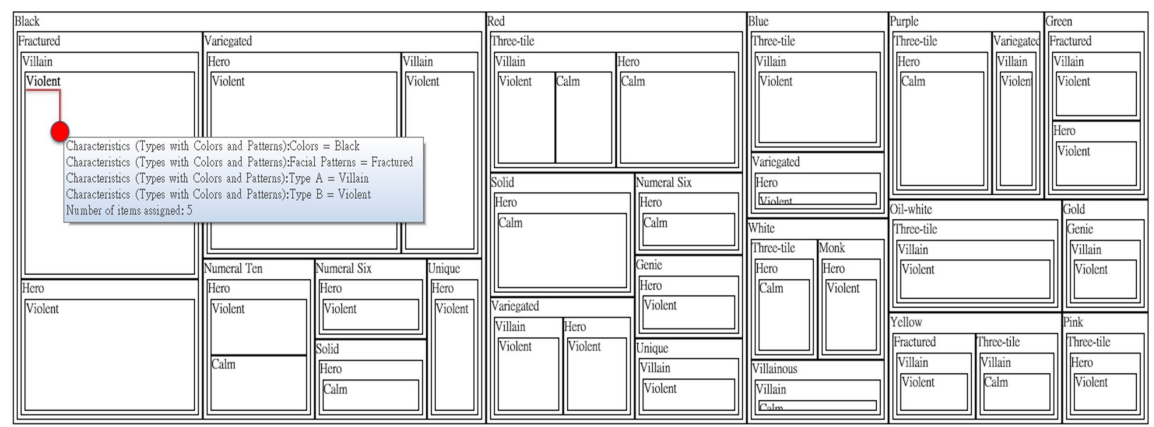

Fig. 9. 48 Painted-faces Compared by Selected Attribute Value Combinations in Nvivo10

Thus, in terms of the relationships among cognitive design on those patterns of masks, the results of this research were what we expected that design factors could be of enormous value to a performer oneself. But both in the social and cognitive dimensions are essential issues for sure in nowadays. For the patterns design competence of Chinese opera painted-face is one thing, but for the naturalization and globalization will be another barrier to conquer in the mass culture society.

\section{References}

1. Wang, S.Z.: The Face of Chinese Opera. Han Guang Culture Press, Taipei (1984)

2. Bao, C.J., Cao, J.: Culture of China: Fascinating Stage Arts. Foreign Languages Press, Beijing (2002)

3. Zhang, B.J.: Chinese Opera and Painted-Face. National Fu-Hsing Dramatic Arts Academy, Taipei (1981)

4. Official Website of Chinese Opera-Peking Opera, http://jinju.koo.org.tw

5. Stokes, J.: How to Do Media and Cultural Studies. SAGE Publications Ltd., London (2013) 